\title{
Antifungal activity of volatile compounds produced by endophytic Bacillus subtilis DZSY21 against Curvularia lunata
}

\author{
Shanshan Xie ${ }^{1 \dagger}$, Juan Liu ${ }^{1,3+}$, Shuangyue Gu${ }^{2}$, Xiaojie Chen ${ }^{2}$, Haiyang Jiang ${ }^{1}$ and Ting Ding ${ }^{2^{*}}$ (D
}

\begin{abstract}
Purpose: To screen endophytic Bacillus producing volatile organic compounds (VOCs) with antifungal activity, and to explore their biocontrol properties toward the growth and pathogenicity of Curvularia lunata.

Methods: Two-sealed-base-plate assays were used to estimate the antifungal activities of Bacillus strains against $C$. lunata. Conjoint analysis of solid-phase microextraction gas chromatography-mass spectrometry and antagonistic experiments were used to identify the VOCs responsible for the antifungal activity. Effects of individual synthetic VOCs were analyzed along with reactive oxygen species (ROS) accumulation in C. lunata conidia. After exposure to individual VOCs, conidia were also sprayed onto maize leaves to evaluate their pathogenicity. Expression levels of virulence-related genes in C. lunata mycelium following exposure to VOCs were analyzed using quantitative realtime PCR.
\end{abstract}

Results: Among the ten endophytic Bacillus strains and two plant growth-promoting rhizobacterial (PGPR) strains, only B. subtilis strain DZSY21 strongly inhibited the growth of C. lunata by producing VOCs. 2-Methylbutyric acid, 2heptanone, and isopentyl acetate produced by strain DZSY21 showed inhibitory effects on the mycelia growth and conidial sporulation of C. lunata. 2-Heptanone and isopentyl acetate also repressed the germination of conidia and the expression levels of virulence-related genes in C. lunata mycelium. Moreover, isopentyl acetate strongly enhanced the accumulation of intracellular ROS in conidia. The disease indexes of maize leaves sprayed with VOCtreated C. lunata conidia were reduced from 60.52 to $26.64 \%$.

Conclusion: Endophytic B. subtilis strain DZSY21 displayed the potential to control C. lunata by producing VOCs, especially 2-heptanone and isopentyl acetate.

Keywords: Gas chromatography-mass spectrometry, 2-Methylbutyric acid, 2-Heptanone, Isopentyl acetate, Disease control

\section{Introduction}

Curvularia lunata is a major pathogen causing leaf spot disease in maize. In 1996, the disease expanded over $192,000 \mathrm{hm}^{2}$, leading to 8 million $\mathrm{kg}$ yield loss in Liaoning Province, China (Dai et al. 1998). On cultivating a disease-resistant variety in a large growing area, the disease came under control and less damage was observed (Gao et al. 2014). However, due to variation of pathogen virulence, the disease has

\footnotetext{
* Correspondence: dingting98@126.com

+Shanshan Xie and Juan Liu contributed equally to this work.

${ }^{2}$ College of Plant Protection, Anhui Agricultural University, Hefei 230036,

China

Full list of author information is available at the end of the article
}

reemerged in recent years and caused great loss of maize in Liaoning, Anhui, and Henan Provinces of China (Gao et al. 2014). Maize leaf spot disease caused by $C$. lunata has become a catastrophic disease, ranking in terms of damage caused behind Southern corn leaf blight, Northern corn leaf blight, and corn smut (Dai et al. 1998). Some research has focused on discovering the disease occurrence pattern and pathogenic mechanisms of C. lunata. Several virulence-related factors, such as cellulase, melanin, and non-host specific toxin methyl 5-(hydroxymethyl)-furan-2-carboxylate (M5HF2C), have been confirmed to be involved in infection by $C$. lunata 
(Xu et al. 2007). Meanwhile, M5HF2C produced by C. lunata also threatens public health (Liu et al. 2010). It has been shown that some natural compounds can control disease caused by C. lunata. For instance, essential oil of Cymbopogon citratus inhibited conidia germination and reduced disease progress (Mourão 2017), and extracts of Cinnamomum zeylanicum exhibited antifungal activity toward $C$. lunata (Mishra et al. 2009). However, there is no effective method to control Curvularia spp. Therefore, it is essential to develop an agent to effectively prevent and control the disease. The application of plant-beneficial microorganisms, which are friendly to the environment and safe for humans, is an alternative to using chemical agents and has attracted increasing attention.

Plant-beneficial microorganisms can promote plant growth and protect plants from pathogen infection. Recently, volatile organic compounds (VOCs) produced by plant-beneficial microorganisms have attracted attention because of their inhibitory effects on pathogens. For example, VOCs (benzothiazoles phenol and 2,3,6-trimethyl-phenol) produced by $\mathrm{Ba}$ cillus amyloliquefaciens NJN-6 could affect the growth and spore germination of Fusarium oxysporum f. sp. cubense (Jun et al. 2012). VOCs produced by Streptomyces fimicarius BWL-H1 inhibited the growth and development of Peronophythora litchii by destroying the integrity of the cell wall (Xing et al. 2018). Several studies have indexed antifungal activities of VOCs produced by endophytic bacteria. B. velezensis ZSY-1 exhibited strong antifungal activity toward Alternaria solani and Botrytis cinerea by producing volatile 2,5-dimethylpyrazine and benzothiazole (Gao et al. 2017). The volatile compound 2-ethyl-3-methylpyrazine produced by $\mathrm{Ba}$ cillus megaterium also showed broad spectrum antimicrobial activity (Munjal et al. 2016).

Endophytic bacteria, living in plant tissues for at least part of their life cycle, do not cause any damage to host plants. Endophytes are found in many plants, such as soybean (Yang et al. 2018), rice (Elbeltagy et al. 2001), and maize (Mousa et al. 2015). During the long-term cooperative evolutionary process, they have developed a mutually beneficial relationship with their host plants through modulation of plant ethylene levels (Hardoim et al. 2008), increasing the availability of nutrients (Santoyo et al. 2016; Liu et al. 2018), producing antimicrobial components (Gond et al. 2015), priming plant innate immunity (Conrath et al. 2015), and enhancing plant tolerance to various abiotic stresses (Subramanian et al. 2015; Sun et al. 2016). The plant tissues where endophytic bacteria live are relatively closed environments, which could be conducive to accumulation of VOCs at the levels required to act on some pathogens. In this regard, endophytic bacterial strains that produce antifungal VOCs could potentially be considered as a means to control pathogens inside infected tissues.

Eucommia ulmoides, a rare and valuable plant, is not easily infected by plant pathogens and insect pests, and is used in Chinese traditional medicine. Besides the possible existence of several biologically active compounds synthesized by this plant species, constitutively or in response to bioaggressors, endophytic microbes with antimicrobial properties could also contribute to plant health (Chen et al. 2010). Previously, we isolated endophytic bacteria from $E$. ulmoides (Ding et al. 2017). Among them, B. subtilis strain DZSY21 also displayed an endophytic lifestyle in maize leaves; its population density reached 6.35 $\times 10^{3}$ colony-forming units (CFU)/g leaf tissue at 15 days post-inoculation, and remained above $2.17 \times$ $10^{3} \mathrm{CFU} / \mathrm{g}$ leaf tissue until 30 days post-inoculation (Ding et al. 2017). Moreover, strain DZSY21 can produce antimicrobial lipopeptides like surfactin and fengycin, suggesting it has the potential to control maize leaf spot disease caused by $C$. lunata. In this study, the VOCs produced by strain DZSY21 that contribute to antifungal activity were identified using gas chromatography-mass spectrometry (GC$\mathrm{MS}$ ), and their mechanisms of action against $C$. lunata were analyzed. This study will help us to better understand the biological control mechanisms of endophytic bacteria from the point of view of VOCs.

\section{Materials and methods}

\section{Microbial strains and culture conditions}

Ten endophytic Bacillus strains previously isolated from the leaves of E. ulmoides at Anhui Agricultural University (31 $\left.86^{\prime} \mathrm{N}, 117^{\circ} 25^{\prime} \mathrm{E}\right)$ (Ding et al. 2017) and two widely known PGPR strains (B. subtilis OKB105 and B. velezensis FZB42) were tested for their antifungal activities. These Bacillus strains were cultured in Luria-Bertani (LB) medium (tryptone 10 $\mathrm{g} / \mathrm{L}, \mathrm{NaCl} 10 \mathrm{~g} / \mathrm{L}$, yeast extract $5 \mathrm{~g} / \mathrm{L}, \mathrm{pH} 7.0$ ) at 37 ${ }^{\circ} \mathrm{C}$ for $12 \mathrm{~h}$. The target pathogenic fungal strain, $C$. lunata, was cultured on potato dextrose agar (PDA) medium (potato $200 \mathrm{~g} / \mathrm{L}$, dextrose $20 \mathrm{~g} / \mathrm{L}$, agar $15 \mathrm{~g} /$ L) at $28{ }^{\circ} \mathrm{C}$ for 7 days.

\section{Antifungal assay of VOCs against $C$. lunata}

Two-sealed-base-plates were used to detect the antifungal activities of VOCs produced by 12 Bacillus strains. Four drops of Bacillus spp. cell suspension in LB medium $\left(5 \mu \mathrm{L}\right.$ per drop, $\left.10^{8} \mathrm{CFU} / \mathrm{mL}\right)$ were 
spotted onto the one-base-plate containing $20 \mathrm{~mL} \mathrm{LB}$ agar medium, and a 5-mm mycelium disk of $C$. lunata was placed on another-base-plate containing $20 \mathrm{~mL}$ PDA agar medium. Plates without the inoculation of Bacillus cell suspensions were used as control. The two-base-plates were sealed and cultured at 28 ${ }^{\circ} \mathrm{C}$. The colony diameters of $C$. lunata were measured every $24 \mathrm{~h}$ for 7 days. Inhibition rate $(\%)=$ (colony diameter exposed to mock - colony diameter exposed to Bacillus VOCs)/colony diameter exposed to mock $\times 100$. Each treatment had five replications, and the assay was repeated three times.

\section{Collection and identification of VOCs produced by strain DZSY21}

The VOCs produced by strain DZSY21 were collected using a 2-cm divinyl benzene/carboxen/PDMS (DCP, $50 / 30 \mu \mathrm{m})$ solid phase microextraction (SPME) fiber (Supelco, Bellefonta, PA, USA). Cell suspensions (20 $\mu \mathrm{L}, 10^{8} \mathrm{CFU} / \mathrm{mL}$ ) of strain DZSY21 were added into LB agar medium in a $100-\mathrm{mL}$ vial covered with several layers of parafilm and incubated at $28{ }^{\circ} \mathrm{C}$ for 7 days without agitation. Uninoculated LB medium was used as the control. SPME fiber was then inserted into the vials and incubated at $50{ }^{\circ} \mathrm{C}$ for $30 \mathrm{~min}$. After that, the SPME fiber was inserted into the GCMS injector (Thermo Scientific ITQ1100, Waltham, MA, USA) and desorbed at $220{ }^{\circ} \mathrm{C}$ for $5 \mathrm{~min}$ (Xie et al. 2018; Jun et al. 2012). The GC-MS program was $35{ }^{\circ} \mathrm{C}$ maintained for $3 \mathrm{~min}$, then increased to $180{ }^{\circ} \mathrm{C}$ at $10{ }^{\circ} \mathrm{C} / \mathrm{min}$, further increased to $240{ }^{\circ} \mathrm{C}$ at $10{ }^{\circ} \mathrm{C} / \mathrm{min}$, and held for $5 \mathrm{~min}$. The mass spectrometer was operated in the electron ionization mode at $70 \mathrm{eV}$ with a source temperature of $220{ }^{\circ} \mathrm{C}$, with scans from $\mathrm{m} / \mathrm{z} 50$ to 500 . Mass spectral data were compared with data in the NIST/EPA/NIH Mass Spectrum Library (Xie et al. 2018). Each treatment had three replications, and the assay was repeated three times.

\section{Antifungal assay of VOCs identified by GC-MS analysis} Three VOCs (2-methylbutyric acid [2-MBA], 2-heptanone [2-HA], and isopentyl acetate [IA]) produced by B. subtilis strain DZSY21 can be purchased from Sigma or Aladdin, and their antifungal activities were individually evaluated using divided Petri dishes. A pure individual VOC $(50 \mu \mathrm{L})$ or control treatment (dimethyl sulfoxide [DMSO] or LB medium) was added to one compartment of a divided Petri dish containing LB agar medium, and a 5-mm mycelium disk of $C$. lunata was placed in the other compartment. Due to the similar negative effects on $C$. lunata at the third day and seventh day, the colony diameters of $C$. lunata were measured after incubating at $28{ }^{\circ} \mathrm{C}$ for 3 days to shortening the period. Furthermore, antifungal effects of different volumes of the three VOCs $(5-50 \mu \mathrm{L})$ were also evaluated to find the minimum inhibitory amount. Fifty-microliter DMSO-treated samples were used as controls. Each treatment had five replications, and the experiment was repeated three times.

\section{Sporulation and germination of $C$. lunata conidia as affected by individual VOCs}

Effects of the VOCs on the sporulation of conidia were tested using divided Petri dishes. For that, $5 \mu \mathrm{L}$ 2 -MBA, $17.5 \mu \mathrm{L} 2-\mathrm{HA}$, or $30 \mu \mathrm{L}$ IA below the minimum inhibitory content or $50 \mu \mathrm{L}$ DMSO as a control were added to one compartment of divided Petri dishes containing LB agar medium, and a 5-mm mycelium disk of $C$. lunata was placed in the other compartment. After co-culturing for 3 days, the conidia were harvested with $5 \mathrm{~mL}$ sterile water, observed, and counted using a hemocytometer under microscopy. Each treatment had five replications, and the experiment was repeated three times.

A 5-mm mycelium disk of C. lunata was placed on PDA medium at $28{ }^{\circ} \mathrm{C}$. After 7 days, the conidia were collected in $5 \mathrm{~mL}$ sterilized water at a concentration of $1 \times 10^{5}$ conidia $/ \mathrm{mL}$. To evaluate the germination rate of conidia, $50 \mu \mathrm{L}$ conidial suspensions were added to one compartment of a divided Petri dish containing PDA medium, and $5 \mu \mathrm{L} 2$-MBA, $17.5 \mu \mathrm{L}$ 2 -HA, or $30 \mu \mathrm{L}$ IA below the minimum inhibitory content or $50 \mu \mathrm{L}$ DMSO as a control were added to the other compartment. After incubating at $28{ }^{\circ} \mathrm{C}$ for $3 \mathrm{~h}$, the samples were observed with a Leica microscope (Wetzlar, Germany), and the germination rate was measured from 150 randomly selected conidia. Each assay was repeated three times.

\section{Reactive oxygen species detection in mycelium and conidia following exposure to individual VOCs}

To detect whether the VOCs affected the generation of ROS in Curvularia cells, the mycelium and conidia were collected after co-culture with $5 \mu \mathrm{L}$ 2-MBA, $17.5 \mu \mathrm{L}$ 2-HA, or $30 \mu \mathrm{L}$ IA below the minimum inhibitory content, or with $50 \mu \mathrm{L}$ DMSO as a control. After culturing at $28{ }^{\circ} \mathrm{C}$ for 3 days, the mycelium and conidia were resuspended in $1 \mathrm{~mL}$ phosphate-buffered saline (PBS) buffer (pH 7.4), 2,7dichlorodi-hydrofluorescein diacetate (DCFH-DA) was added to a final concentration of $10 \mu \mathrm{M}$, and then the material was incubated at $37{ }^{\circ} \mathrm{C}$ for $20 \mathrm{~min}$, according to the instructions of the Reactive Oxygen Species Assay Kit (Beyotime Biotechnology, China). The samples were finally observed using a Zeiss laser confocal microscope LSM800 (excitation $488 \mathrm{~nm}$; emission $535 \mathrm{~nm}$ ). Fluorescence intensities were analyzed using the ImageJ software (Rawak Software Inc., Germany) from 30 randomly selected conidia 
and mycelia. Each treatment had five replications, and the experiment was repeated three times.

\section{Disease development on maize leaves inoculated with VOC-treated C. lunata conidia}

Seeds of maize B73 inbred lines were obtained from the Maize Genetics Cooperation Stock Center (http:// maizecoop.cropsci.uiuc.edu/). C. lunata conidia were collected after co-culture with $5 \mu \mathrm{L} 2-\mathrm{MBA}, 17.5 \mu \mathrm{L} 2-$ $\mathrm{HA}$, or $30 \mu \mathrm{L}$ IA below the minimum inhibitory content, or with $50 \mu \mathrm{L}$ DMSO as a control. After culturing at $28^{\circ} \mathrm{C}$ for 3 days, the conidia were resuspended $\left(1 \times 10^{6}\right.$ conidia/ $\mathrm{mL}$ ) in a solution containing $2 \%$ glucose and $0.02 \%$ Tween 20. Then, the conidial suspensions were used to spray maize leaves ( $5 \mathrm{~mL}$ per leaf) of plants at the four-leaf stage grown in a greenhouse. Seven days later, the disease severity was evaluated using a rating scale from 0 to $4: 0=$ no leaf spot observed, 1 = incidence area $\leq 25 \%, 2=$ incidence area 26 to $50 \%, 3=$ incidence area 51 to $74 \%$, and $4=$ incidence area $\geq 75 \%$. The disease index was calculated for each maize seedling according to the formula: disease index $(\%)=\sum\left(d_{i} \times I_{i}\right) /(d \times N) \times 100$, where $d_{i}=$ the grade of disease severity, with $i$ varying from 0 to $4 ; I_{\mathrm{i}}=$ the number of leaves with different grades of disease; $d=$ the highest grade of disease severity; and $N=$ the number of investigated leaves. Each treatment had three replications, and the experiment was repeated three times.

\section{Expression levels of virulence-related genes in C. lunata mycelium following exposure to individual VOCs}

A 5-mm mycelium disk of $C$. lunata was placed in the one compartment of a divided Petri dish containing PDA medium at $28{ }^{\circ} \mathrm{C}$. Three days later, $5 \mu \mathrm{L}$ 2-MBA, $17.5 \mu \mathrm{L}$ 2-
HA, $30 \mu \mathrm{L}$ IA below the minimum inhibitory content or 50 $\mu \mathrm{L}$ DMSO (as a control) were added to the other compartment. After co-culturing for $24 \mathrm{~h}$, the C. lunata mycelia were scraped off with a sterilized medicine spoon and ground into powder in liquid nitrogen. Total RNA was extracted with TaKaRa RNAiso reagent, and first-strand cDNA was synthesized using reverse transcriptase with oligo (dT) primer (TaKaRa Bio, Dalian, China). Quantitative real-time PCR analysis was performed with TB Green ${ }^{\circ}$ Premix Ex Taq $^{\mathrm{TM}}$ II (TaKaRa Bio) on a 7300 Real-Time PCR System (Applied Biosystems, Foster City, CA, USA) according to our previous study (Ding et al. 2017). GAPDH was used as an internal reference gene, and the expression levels of virulence-related genes clk1 and $\operatorname{clm} 1$ (two mitogen-activated protein kinases), clt (regulating non-host specific toxin M5HF2C), and scd and brn1 (which participate in melanin synthesis) were analyzed according to $2^{-\triangle \Delta \mathrm{ct}}$ method (Liu et al. 2011; Wang and Chen 2011; Gao et al. 2013). Primer sequences for these genes are listed in Table S1. Each treatment had three replications, and the experiment was repeated three times.

\section{Statistical analysis}

Data normality was verified in the SPSS software (SPSS Inc. Chicago, USA) with P-P plots, and the data were then analyzed by Fisher's least-significant difference test $(P<$ 0.05 ) using the SPSS software.

\section{Results}

\section{Screening for bacteria producing VOCs with antifungal} activity

Ten endophytic Bacillus strains previously isolated from E. ulmoides as well as two well-known PGPR strains (B.
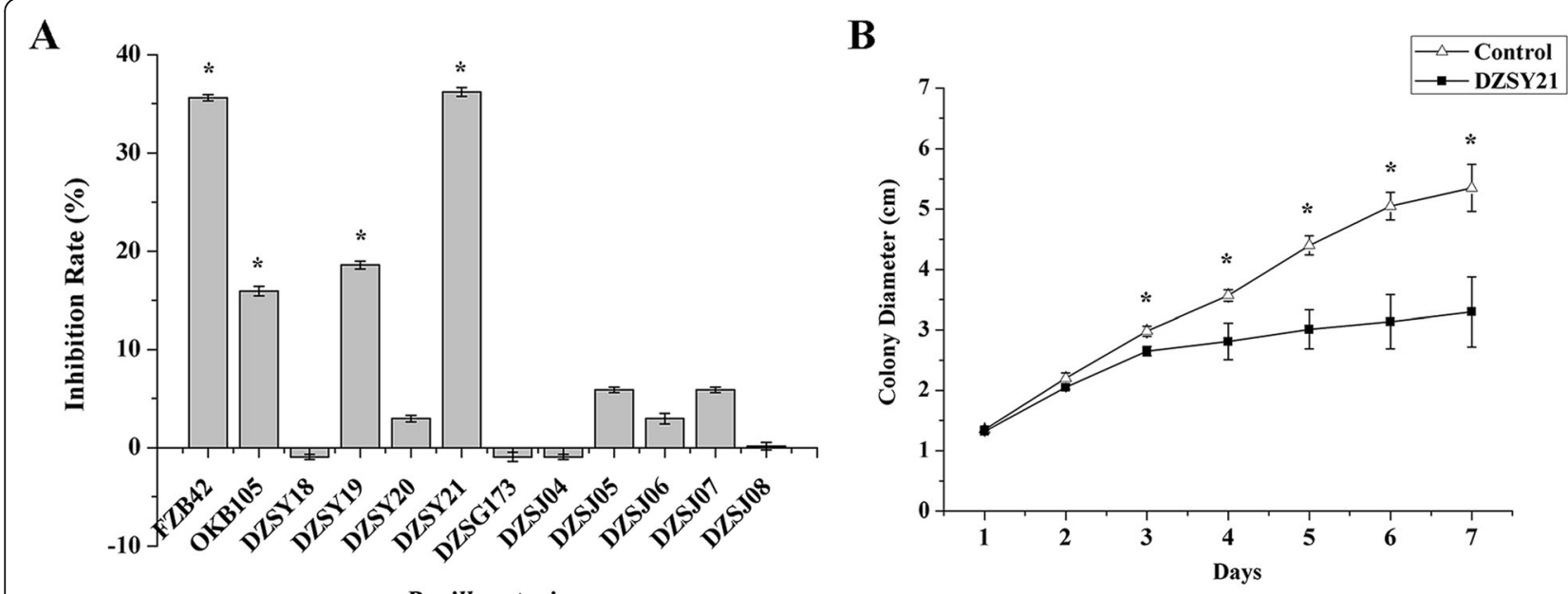

Bacillus strains

Fig. 1 Screening for Bacillus strains producing volatile organic compounds (VOCs) with antifungal activity against C. lunata. a The inhibition rates of C. lunata exposed to Bacillus VOCs were measured on the seventh day. $\mathbf{b}$ Colony diameters of C. lunata exposed to B. subtilis DZSY21 VOCs. The colony diameters were measured every $24 \mathrm{~h}$ for 7 days. Each treatment contained five replications, and the assay was repeated three times. ${ }^{*}$ A significant difference compared with the control $(P<0.05)$. Error bars represent the standard deviation 


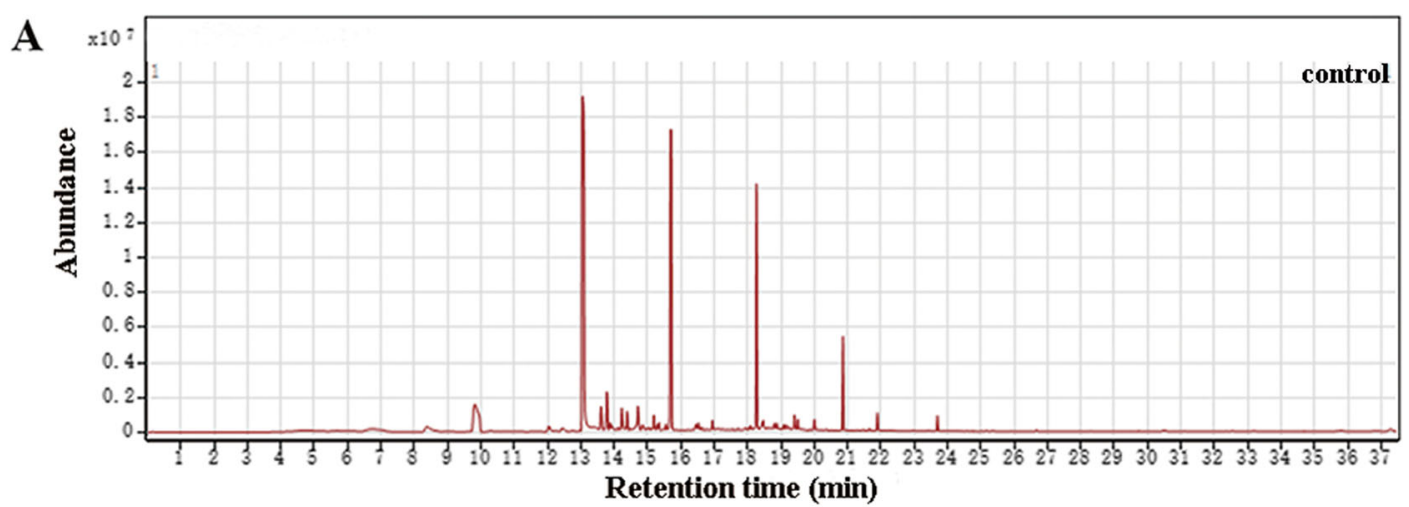

B
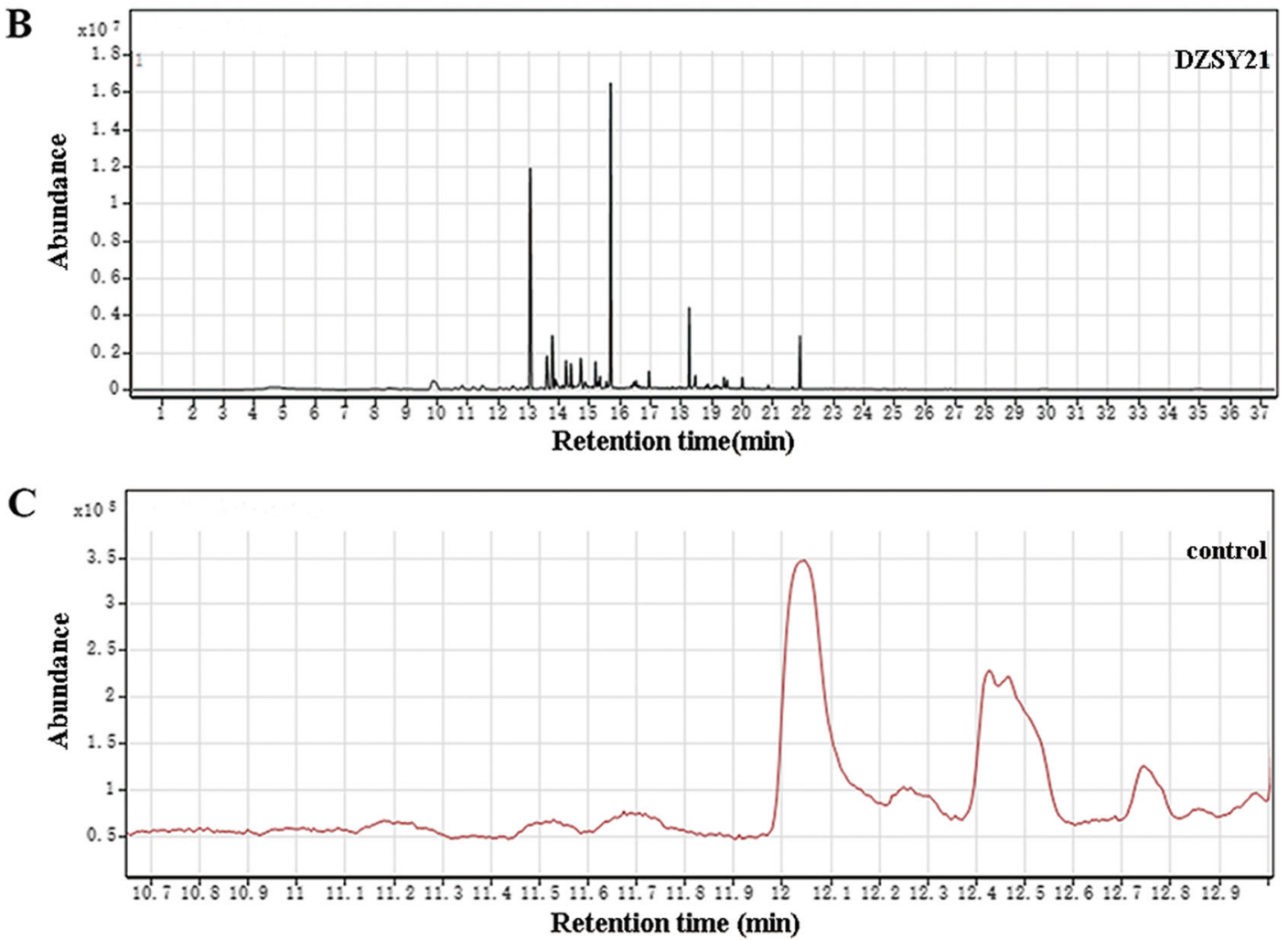

D

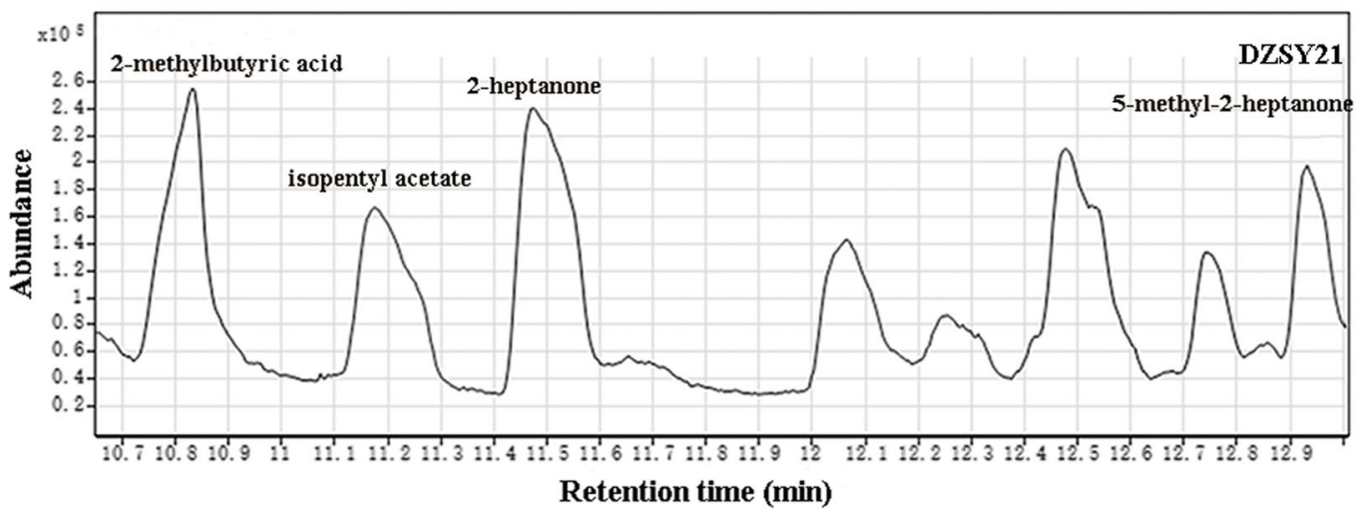

Fig. 2 Solid-phase microextraction gas chromatography-mass spectrometry identification of VOCs produced by B. subtilis DZSY21. Global chromatographic profiles of VOCs from Luria-Bertani (LB) medium (a) and strain DZSY21 (b). Local chromatographic profiles (zoom into the global chromatographic profile from 10 to 13 min) of VOCs from LB medium (c) and strain DZSY21 (d) 
subtilis OKB105 and B. velezensis FZB42) were tested for their antifungal activities using two-sealed-base-plate assays. Preliminary screening showed that the VOCs produced by endophytic strains DZSY19 and DZSY21 significantly $(P<0.05)$ inhibited the growth of $C$. lunata, and the inhibition rate of DZSY21 (36.2\%) was similar to the effect of commercial PGPR strain FZB42 (Fig. 1a). As shown in Fig. 1b, the growth of $C$. lunata was suppressed $(P<0.05)$ by the third day of exposure to DZSY21. The inhibition effect was maintained for the rest of the co-culture. Because of this promising antifungal activity, endophytic strain DZSY21 was selected for further study.

\section{Identification of VOCs produced by DZSY21 and their antifungal activities}

GC-MS analysis detected $>20$ VOCs produced by culture of strain DZSY21 in LB medium, although many were also detected in the medium without bacterial inoculation (Fig. 2a, b). 2-MBA, 2-HA, IA, and 5methyl-2-heptanone were identified as compounds specifically produced by strain DZSY21 (Fig. 2c, d). Among these VOCs, 2-MBA, 2-HA, and IA are available commercially, and their antifungal activities were further analyzed. All three VOCs inhibited the growth of $C$. lunata after exposure for 3 days (Fig. 3a). The inhibitory effects were dose-dependent; $10 \mu \mathrm{L} 2-\mathrm{MBA}, 20 \mu \mathrm{L} 2-\mathrm{HA}$, and $35 \mu \mathrm{L}$ IA were the minimum amounts required to inhibit the growth of C. lunata on exposure for 3 days (Fig. 3b-d).

\section{Effects of three individual VOCs produced by strain DZSY21 on the sporulation and germination of C. lunata conidia}

All three VOCs significantly $(P<0.05)$ inhibited the sporulation of $C$. lunata below their minimum inhibitory amount (Fig. 4a). Sporulation in the presence of $2-\mathrm{MBA}, 2-\mathrm{HA}$, and IA treatment reduced to $33 \%$ or

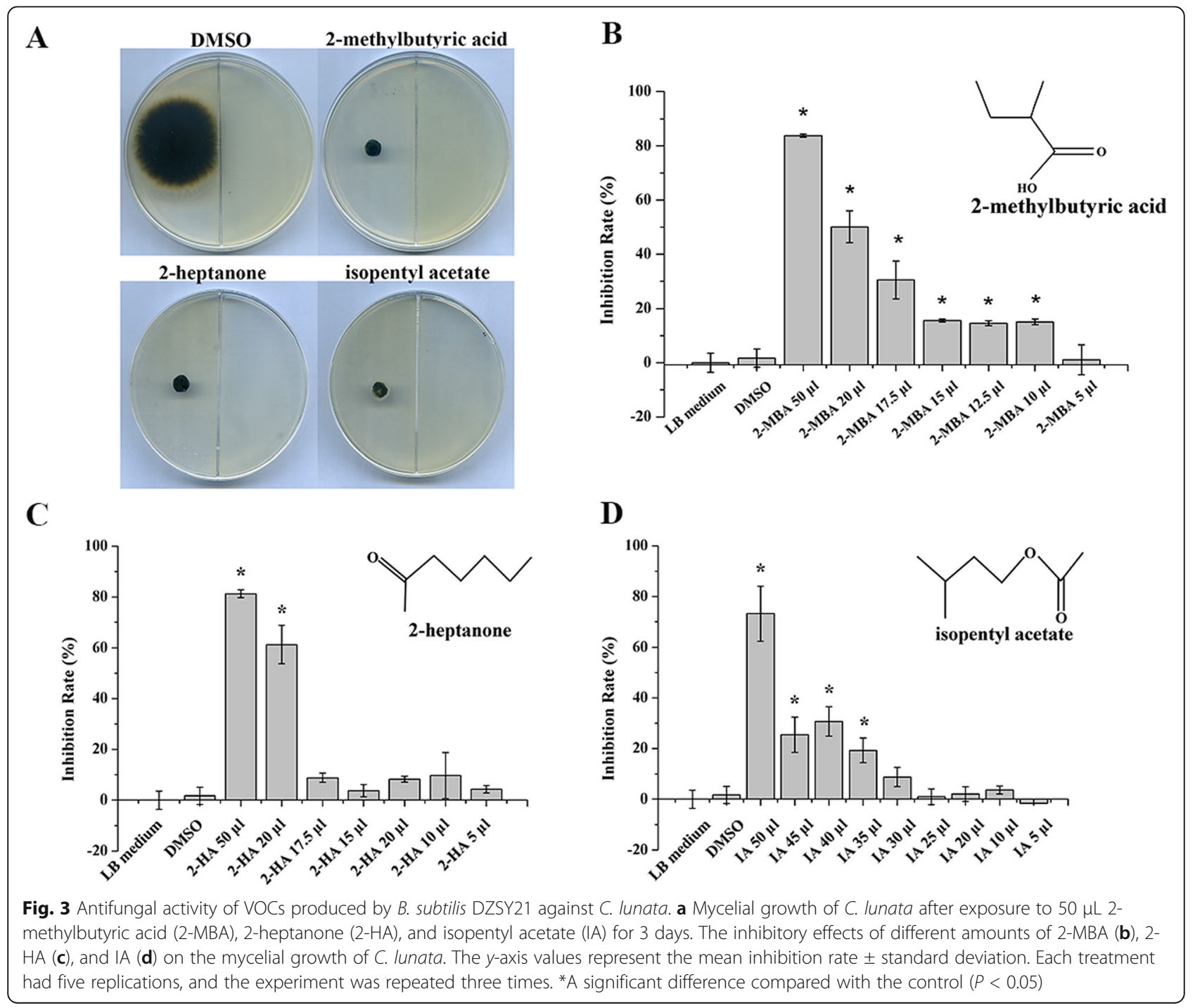




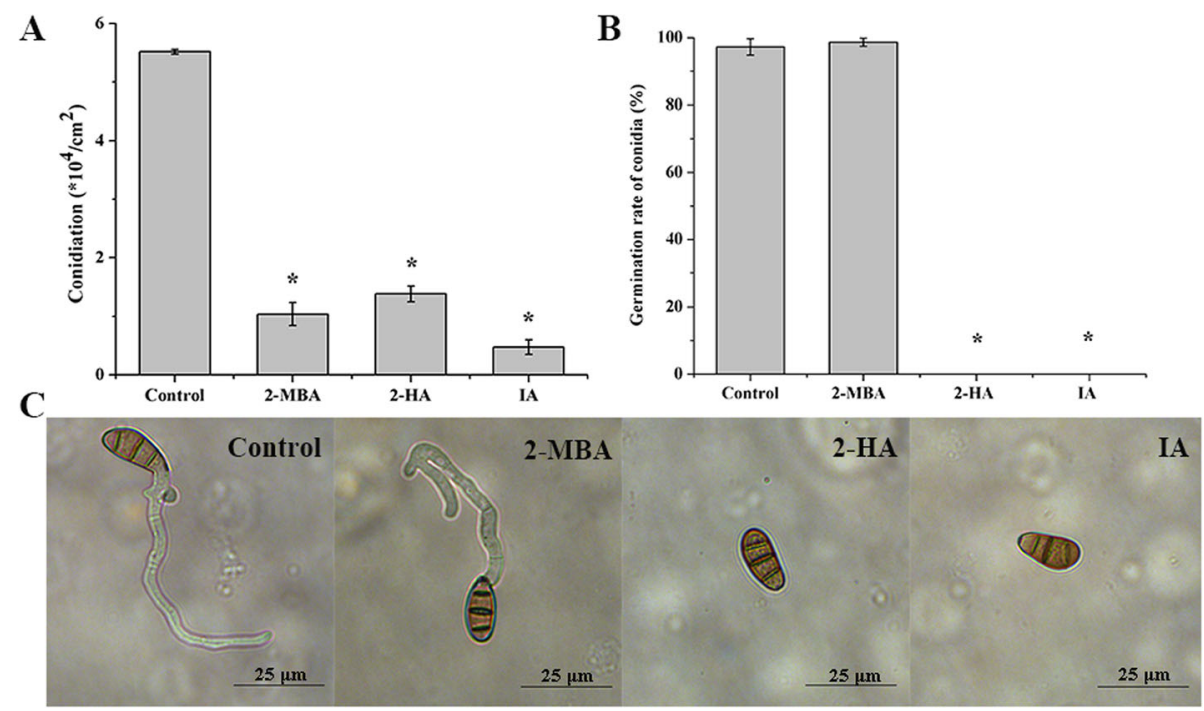

Fig. 4 Effects of VOCs produced by B. subtilis DZSY21 on the sporulation and germination of C. lunata conidia. a Sporulation of C. lunata after treatment with $5 \mu \mathrm{L} 2-\mathrm{MBA}, 17.5 \mu \mathrm{L} 2-\mathrm{HA}$, or $30 \mu \mathrm{L}$ IA below their minimum inhibitory amounts. $\mathbf{b}$ Germination rates of C. Iunata conidia after exposure to $5 \mu \mathrm{L}$ 2-MBA, $17.5 \mu \mathrm{L} 2-\mathrm{HA}$, or $30 \mu \mathrm{L}$ IA below their minimum inhibitory amounts. c Image capture of conidial germination after exposure to the VOCs below their minimum inhibitory amounts (magnification $16 \times 20)$. ${ }^{*} \mathrm{~A}$ significant difference compared with the control $(P<$ 0.05). Error bars represent the standard deviation. The assay was repeated three times

more compared with control treatment. The influence of VOCs on conidia germination was further investigated. The conidia could germinate normally in the control, or 2-MBA treatment, whereas almost no germinated conidia were observed in the 2-HA and IA treatments (Fig. 4b, c).

\section{IA caused the generation of intracellular ROS in C. lunata conidia}

2-MBA - and 2-HA-treated mycelium and conidia of C. lunata showed the same green fluorescence intensity as control (DMSO)-treated samples. However, stronger green fluorescence was observed in IAtreated conidia (Fig. 5a and Fig. S1). Subsequent fluorescence intensity quantification confirmed the result, and the fluorescence intensity in IA-treated conidia was three times than that in control-treated conidia (Fig. 5b).

\section{Effects of the three individual VOCs produced by $B$.}

subtilis DZSY21 on the disease index of maize leaves and the expression levels of $C$. lunata virulence-related genes The disease indexes of maize leaves sprayed with VOCtreated $C$. lunata conidia were lower than that of the control (Fig. 6a), and the decrease of the disease index was similar for each of the VOCs. qRT-PCR analysis showed that the expression levels of all five tested virulence-related genes were downregulated in C. lunata mycelium after exposure to 2-HA, four genes (but not clt) were repressed in response to IA, and the expression levels of $\operatorname{lm} 1$ and $b r n 1$ were repressed in response to 2MBA (Fig. 6b).

\section{Discussion}

E. ulmoides shows good resistance to pathogens and insect pests. Besides the possible existence of several biologically active compounds synthetized by this plant species, constitutively or in response to bioaggressors, endophytic microbes with antimicrobial properties could also contribute to plant health. Hence, endophytes isolated from E. ulmoides tissue may take part to its health by exhibiting antimicrobial properties (Chen et al. 2010; Ding et al. 2017). In this study, we evaluated the antifungal activities of VOCs produced by ten endophytic Bacillus strains isolated from E. ulmoides. Among them, only two strains displayed significant antifungal activity toward $C$. lunata contrary to our expectations. The VOCs produced by B. subtilis strain DZSY21 significantly inhibited mycelia growth of $C$. lunata by the third day of treatment, and the inhibition rate reached $36.2 \%$ by the seventh day. Conjoint analysis of SPME-GC-MS and antagonistic experiments indicated that the volatile compounds 2-MBA, 2-HA, and IA were responsible for the antifungal activity toward $C$. lunata.

2-HA, which is widely present in nature, has been shown to serve as a pheromone in some insect species (Torto et al. 2007). 2-HA released from B. nematocida B16 contributes to trapping and infecting Caenorhabditis elegans (Zhang et al. 2016). Furthermore, B. amyloliquefaciens DA12 


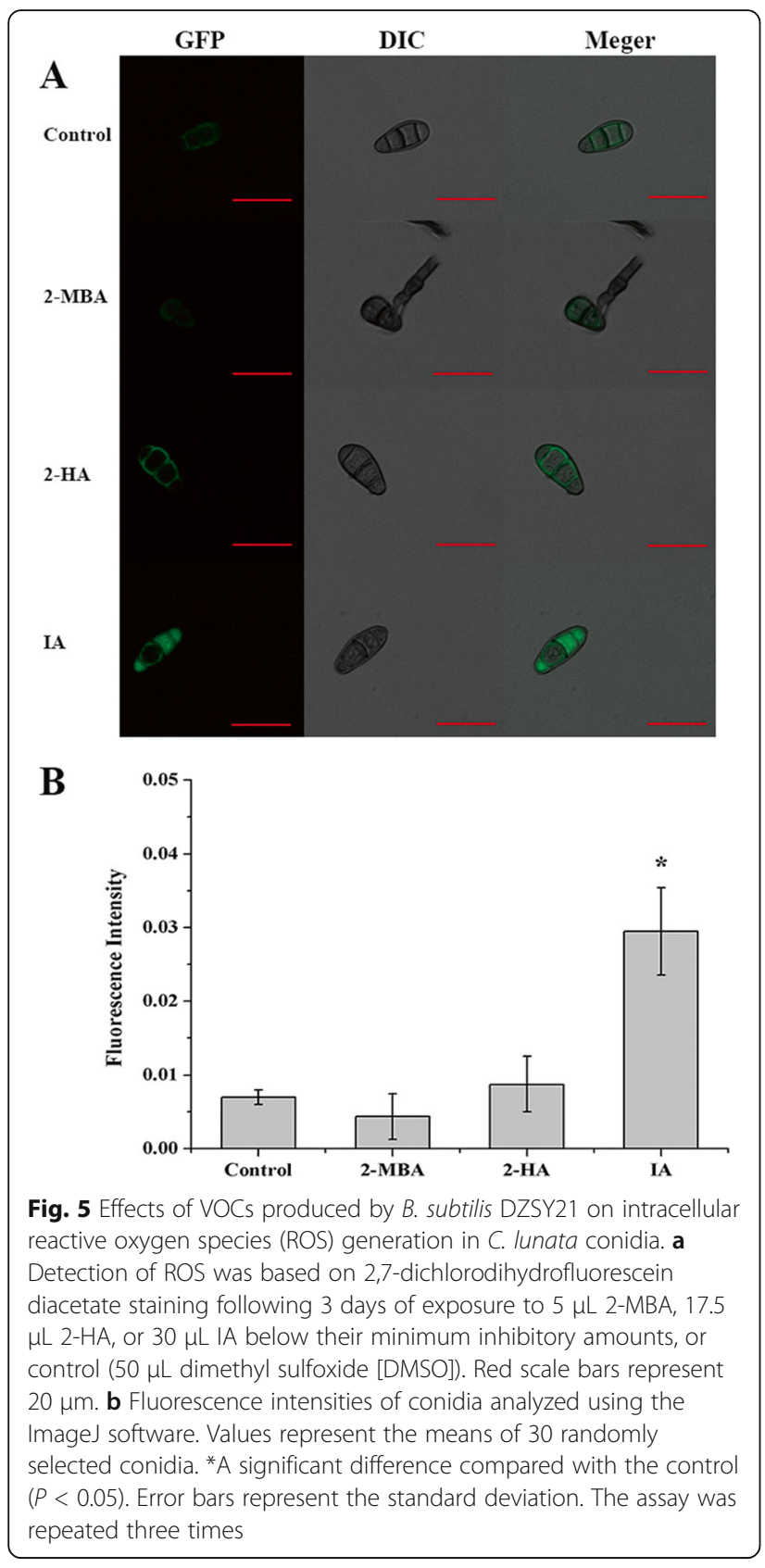

exhibited great antagonistic activities toward various fungal pathogens by producing iturin $\mathrm{A}$ and heptanone (Lee et al. 2017). IA, naturally produced by banana, exhibited strong activity against Escherichia coli by damaging cell membranes and altering protein expression (Ando et al. 2015). 2-MBA, a carboxylic acid compound, has two enantiomeric forms $[(R)$ - and $(S)$ 2-methylbutyric acid] and is naturally produced by plants (Swift 1999). However, antifungal activities of IA and 2-MBA have not previously been reported. Here, the antifungal activities of 2-MBA, 2-HA, and IA produced by strain DZSY21 suggest that these naturally occurring VOCs may have the potential for development into biological control agents.

During the interaction process between plants and pathogenic fungi, the conidia (asexual spores) of Curvularia first adhere to leaf surfaces and germinate to form appressoria; the melanin present in appressoria can aid mechanical strength to penetrate host tissues (Lanisnik and Wheeler 2003). Curvularia also secrete enzymes, such as pectinase, cellulase, and hemicellulase, to degrade host cell walls, eventually facilitating the infection process (Xue et al. 2010). Hence, the sporulation and germination of conidia are important for the spreading of C. lunata. In this study, 2-HA and IA produced by strain DZSY21 strongly inhibited the sporulation and germination of $C$. lunata conidia, while 2-MBA inhibited sporulation, but had no effect on germination. ROS can damage DNA replication and cell membranes, and lead to cell death. Here, IA caused ROS accumulation in the conidia of C. lunata, although 2-HA and 2-MBA had no effect on ROS accumulation in conidia and mycelia. This effect of IA on ROS accumulation in conidia could partly explain the inhibition of their germination, whereas 2-HA probably targeted another cellular process associated with germination. In addition, the VOCs also repressed the expression levels of virulence-associated genes ( $c l k 1, c l m 1, s c d$, and brn1). Among them, $c l k 1$ and $c l m 1$ encoding mitogen-activated protein kinases are required for conidia sporulation and pathogenicity in $C$. lunata (Wang and Chen 2011; Gao et al. 2013). scd and brn1 are involved in the synthesis of melanin (Liu et al. 2011). The inhibitory effect of IA on scd and brn1 expression was higher than that of 2-HA. These results may suggest that the mechanism by which 2-HA inhibits spore germination and pathogenicity of Curvularia is different from that of IA. Due to the effects described above, the disease severities caused by C. lunata conidia were reduced after they were exposed to 2-MBA, 2-HA, and IA before application to maize plants.

Compared with PGPR, endophytic bacteria can establish a close and isolated relationship with plants; thus, the VOCs produced by endophytic bacteria may reach their effective concentrations more easily inside plants than in the rhizosphere. In our previous study, B. subtilis DZSY21 proved able to effectively colonize the inside of maize leaves, and showed a strong inhibitory effect against Bipolaris maydis (Ding et al. 2017). Therefore, endophytic bacteria producing specific VOCs could contribute to the prevention and control of plant disease. Nevertheless, the diversity of VOCs produced by bacteria is highly dependent on their growth substrate (Bailly and Weisskopf 2012). The VOCs with antifungal activity produced by endophytic B. subtilis DZSY21 that we identified in this 


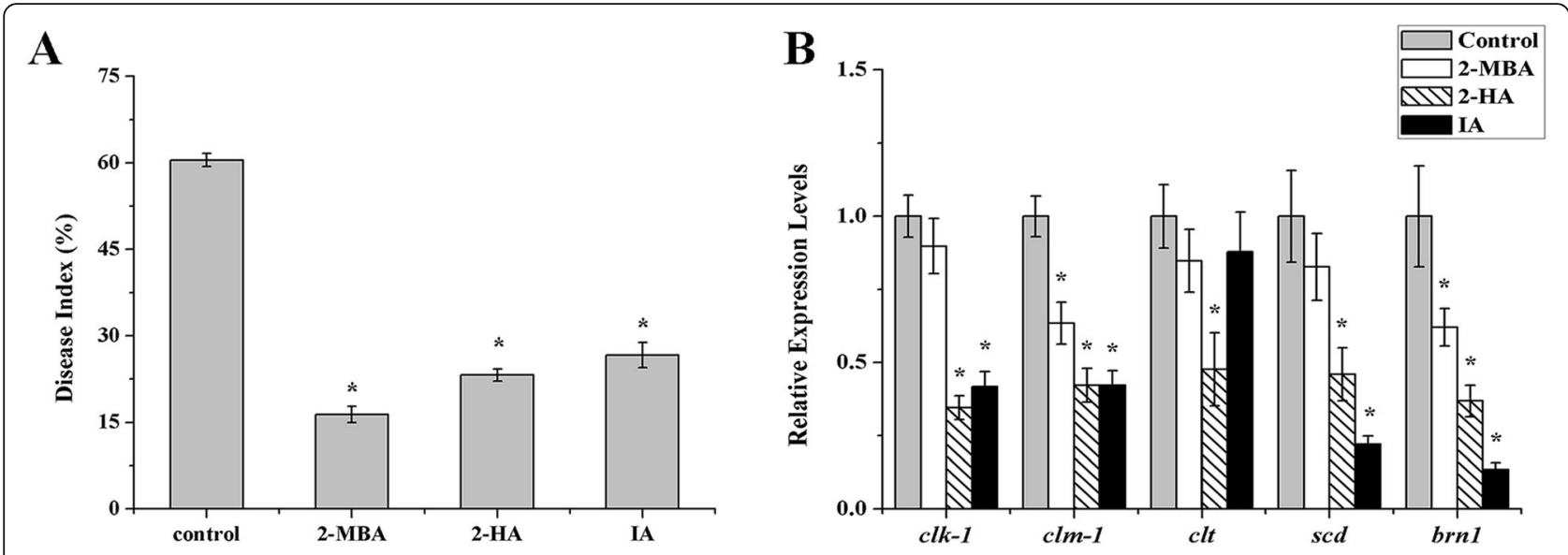

Fig. 6 Effects of VOCS produced by B. subtilis DZSY21 on the disease indexes of maize leaves and the expression levels of $C$. lunata virulencerelated genes. a Disease indexes of maize leaves infected with 2-MBA, 2-HA, IA, or control (DMSO)-treated C. Iunata conidia. b Quantitative realtime PCR analysis of the expression levels of five virulence-related genes ( $c l k 1, c l m 1, c l t, s c d$, and $b r n 1)$ in response to 2-MBA, 2-HA, IA, or control treatment. Values were normalized to the levels of GAPDH, an internal reference gene. The $y$-axis values represent the fold changes of virulencerelated gene expression levels. ${ }^{*}$ A significant difference compared with the control $(P<0.05)$. Error bars represent the standard deviation. Each treatment had three replications, and the experiment was repeated three times

study were obtained after growth in LB medium, which, unlike plant leaves, contains a high level of organic nitrogen. This major chemical difference could lead to different composition and concentrations of VOCs emitted by the bacterium within plant tissues. Further investigation is thus needed to better resolve the identity and antifungal properties of the VOCs emitted by endophytic $B$. subtilis DZSY21 in maize leaves, for instance by culturing the bacterium in a medium enriched with maize leaf extracts.

\section{Conclusions}

2-Methylbutyric acid, 2-heptanone, and isopentyl acetate produced in vitro by endophytic B. subtilis strain DZSY21 growing on LB medium were capable of inhibiting the in vitro growth of $C$. lunata and the sporulation of conidia. In addition, both 2-HA and IA inhibited the germination of conidia, and IA strongly enhanced the accumulation of intracellular ROS in conidia. Because of these effects, the disease indexes of maize leaves sprayed with VOC-treated C. lunata conidia were reduced by $44 \%$.

\section{Supplementary information}

Supplementary information accompanies this paper athttps://doi.org/10. 1186/s13213-020-01553-0.

Additional file 1: Table S1. Microbial strains used in this study. Table S2. DNA primers used in this study. Figure S1. Effects of individual VOCs produced by B. subtilis DZSY21 on intracellular reactive oxygen species generation in C. lunata mycelium. C. lunata mycelium following 3 days of exposure to $5 \mu \mathrm{L}$ 2-MBA, $17.5 \mu \mathrm{L} 2-\mathrm{HA}, 30 \mu \mathrm{L}$ IA below their minimum inhibitory amounts, or control (50 $\mu \mathrm{L}$ DMSO) was collected, incubated with DCFH-DA at $37^{\circ} \mathrm{C}$ for $20 \mathrm{~min}$, and then rinsed twice with phosphatebuffered saline. The samples were observed using a Zeiss laser confocal microscope LSM800. Scale bars represent $20 \mu \mathrm{m}$.

\section{Acknowledgements}

We thank James Allen, DPhil, from Liwen Bianji, Edanz Group China (www. liwenbianji.cn/ac) for editing the English text of a draft of this manuscript.

\section{Authors' contributions}

Shuangyue Gu and Xiaojie Chen screened the bacteria, Shanshan Xie and Juan Liu identified the VOCs produced by DZSY21, Shanshan Xie, Juan Liu and Haiyang Jiang evaluated the effects of VOCs on formation of conidia and ROS, Ting Ding and Shanshan Xie designed the experiment. The authors read and approved the final manuscript.

\section{Funding}

This work was supported by grants from the National Key Research and Development Plan (2017YFD0201106) and the Talent Research Foundation of Anhui Agricultural University (yj2018-11, 2017H116).

\section{Ethics approval and consent to participate}

This article does not contain any studies with human participants or animals performed by any of the authors.

\section{Consent for publication}

Not applicable.

\section{Competing interests}

The authors declare that they have no competing interests.

\section{Author details}

${ }^{1}$ The National Key Engineering Lab of Crop Stress Resistance Breeding, College of Life Sciences, Anhui Agricultural University, Hefei 230036, China. ${ }^{2}$ College of Plant Protection, Anhui Agricultural University, Hefei 230036, China. ${ }^{3}$ College of Horticulture, Anhui Agricultural University, Hefei 230036, China.

Received: 28 June 2019 Accepted: 29 January 2020

Published online: 24 February 2020

\section{References}

Ando H, Kurata A, Kishimoto N (2015) Antimicrobial properties and mechanism of volatile isoamyl acetate, a main flavour component of Japanese sake (Ginjo-shu). J Appl Microbiol 118:873-880

Bailly A, Weisskopf $L$ (2012) The modulating effect of bacterial volatiles on plant growth: current knowledge and future challenges. Plant Signal Behav 7:79-85 
Chen X, Sang X, Li S et al (2010) Studies on a chlorogenic acid-producing endophytic fungi isolated from Eucommia ulmoides Oliver. J Ind Microbiol Biotechnol 37:447-454

Conrath U, Beckers GJ, Langenbach CJ et al (2015) Priming for enhanced defense. Annu Rev Phytopathol 53:97-119

Dai F, Wang X, Zhu Z (1998) Study on the maize Curvularia leaf spot caused by Curvularia lunata. Acta Phytopathologica Sinica 28:123-129

Ding T, Su B, Chen X et al (2017) An endophytic bacterial strain isolated from Eucommia ulmoides inhibits southern corn leaf blight. Front Microbiol 8:903

Elbeltagy A, Nishioka K, Sato T et al (2001) Endophytic colonization and in planta nitrogen fixation by a Herbaspirillum sp. isolated from wild rice species. Appl Environ Microbiol 67:5285-5293

Gao S, Li Y, Gao J et al (2014) Genome sequence and virulence variation-related transcriptome profiles of Curvularia lunata, an important maize pathogenic fungus. BMC Genomics 15:627

Gao SG, Zhou FH, Liu T et al (2013) A MAP kinase gene, Clk1, is required for conidiation and pathogenicity in the phytopathogenic fungus Curvularia lunata. J Basic Microbiol 53:214-223

Gao Z, Zhang B, Liu H et al (2017) Identification of endophytic Bacillus velezensis ZSY-1 strain and antifungal activity of its volatile compounds against Alternaria solani and Botrytis cinerea. Biol Control 105:27-39

Gond SK, Bergen MS, Torres MS et al (2015) Endophytic Bacillus spp. produce antifungal lipopeptides and induce host defence gene expression in maize. Microbiol Res 172:79-87

Hardoim PR, van Overbeek LS, Elsas JD (2008) Properties of bacterial endophytes and their proposed role in plant growth. Trends Microbiol 16:463-471

Jun Y, Waseem R, Qirong S et al (2012) Antifungal activity of Bacillus amyloliquefaciens NJN-6 volatile compounds against Fusarium oxysporum f. sp. cubense. Appl Environ Microbiol 78:5942-5944

Lanisnik RT, Wheeler MH (2003) Melanin biosynthesis in the fungus Curvularia lunata (teleomorph: Cochliobolus lunatus). Can J Microbiol 49:110-119

Lee T, Park D, Kim K et al (2017) Characterization of Bacillus amyloliquefaciens DA12 showing potent antifungal activity against mycotoxigenic Fusarium species. Plant Pathol J 33:499-507

Liu F, Xu Y, Han G et al (2018) Identification and functional characterization of a maize phosphate transporter induced by mycorrhiza formation. Plant Cell Physiol 59:1683-1694

Liu T, Liu LX, Jiang X et al (2010) A new furanoid toxin produced by Curvularia lunata, the causal agent of maize Curvularia leaf spot. Can J Plant Pathol 31:22-27

Liu T, Xu S, Liu L et al (2011) Cloning and characteristics of Brn 1 gene in Curvularia lunata causing leaf spot in maize. Eur J Plant Pathol 131:211-219

Mishra AK, Amita M, Kehri HK et al (2009) Inhibitory activity of Indian spice plant Cinnamomum zeylanicum extracts against Alternaria solani and Curvularia lunata, the pathogenic dematiaceous moulds. Ann Clin Microbiol Antimicrob 8:9

Mourão DSC, Ferreira de Souza Pereira T, Souza DJ et al (2017) Essential oil of Cymbopogon citratus on the control of the Curvularia leaf spot disease on maize. Medicines 4: e62.

Mousa WK, Shearer CR, Limay-Rios V et al (2015) Bacterial endophytes from wild maize suppress Fusarium graminearum in modern maize and inhibit mycotoxin accumulation. Front Plant Sci 6:805

Munjal V, Nadakkakath AV, Sheoran N et al (2016) Genotyping and identification of broad spectrum antimicrobial volatiles in black pepper root endophytic biocontrol agent, Bacillus megaterium BP17: theory and applications in pest management. Biol Control 92:66-76

Santoyo G, Moreno-Hagelsieb G, Orozco-Mosqueda Mdel C et al (2016) Plant growth-promoting bacterial endophytes. Microbiol Res 183:92-99

Subramanian P, Mageswari A, Kim K et al (2015) Psychrotolerant endophytic Pseudomonas spp. OB155 and OS261 induced chilling resistance in tomato plants (Solanum lycopersicum Mill.) by activation of their antioxidant capacity. Mol Plant-Microbe Interact 28:1073-1081

Sun L, Wang X, Li Y (2016) Increased plant growth and copper uptake of host and non-host plants by metal-resistant and plant growth-promoting endophytic bacteria. Int J Phytoremediation 18:494-501

Swift KAD (1999) Current topics in flavours and fragrances: towards a new millennium of discovery. Springer Netherlands, pp 52

Torto B, Boucias DG, Arbogast RT (2007) Multitrophic interaction facilitates parasite-host relationship between an invasive beetle and the honey bee. Proc Natl Acad Sci U S A 104:8374-8378

Wang JY, Chen J (2011) Cloning and functional analysis of Clm1 in Curvularia lunata. Acta Phytopathologica Sinica 41:464-472
Xie S, Zang H, Wu H et al (2018) Antibacterial effects of volatiles produced by Bacillus strain D13 against Xanthomonas oryzae pv. oryzae. Mol Plant Patho 19:49-58

Xing $M$, Zheng $L$, Deng $Y$ et al (2018) Antifungal activity of natural volatile organic compounds against Litchi downy blight pathogen Peronophythora litchii. Molecules 23:358

Xu S, Chen J, Liu L et al (2007) Proteomics associated with virulence differentiation of Curvularia lunata in maize in China. J Integr Plant Biol 49: 487-496

Xue CS, Zhao ZW, Xiao SQ et al (2010) Infection process of Curvularia lunata on corn leaf observed in incompatible interaction. J Maize Sci 18:139-141

Yang H, Ye W, Ma J et al (2018) Endophytic fungal communities associated with field-grown soybean roots and seeds in the Huang-Huai region of China. Peerj 6:e4713

Zhang C, Zhao N, Chen Y (2016) The signaling pathway of Caenorhabditis elegans mediates chemotaxis response to the attractant 2-heptanone in a Trojan Horse'- like pathogenesis. J Biol Chem 291:23618-23627

\section{Publisher's Note}

Springer Nature remains neutral with regard to jurisdictional claims in published maps and institutional affiliations.

Ready to submit your research? Choose BMC and benefit from:

- fast, convenient online submission

- thorough peer review by experienced researchers in your field

- rapid publication on acceptance

- support for research data, including large and complex data types

- gold Open Access which fosters wider collaboration and increased citations

- maximum visibility for your research: over $100 \mathrm{M}$ website views per year

At $\mathrm{BMC}$, research is always in progress.

Learn more biomedcentral.com/submissions 